\title{
Social Origin, Field of Study and Career Progression: Heterogeneity in Graduates' Occupational Mobility
}

A revised version of this paper with the title "Social Origin, Field of Study, and Graduates' Career Progression: Does Social Inequality Vary Across Fields?" has been accepted for publication in the British Journal of Sociology.

Marita Jacob ${ }^{\mathrm{a}}$, Markus Klein ${ }^{\mathrm{b}}$

${ }^{a}$ Corresponding author, University of Cologne, Institute of Sociology and Social Psychology, Greinstraße 2, 50939 Cologne, Germany, marita.jacob@uni-koeln.de

${ }^{\mathrm{b}}$ University of Strathclyde, School of Education, 141 St James Street, G4 OLT Glasgow, markus.klein@strath.ac.uk

Keywords: social origin, field of study, occupational prestige, career, social inequality

\section{Acknowledgments}

The authors gratefully acknowledge the participants in the 1970 British Cohort Study (BCS70) for providing their information, the Centre for Longitudinal Studies at the Institute of Education, University of London for collecting and managing the data, the Economic and Social Research Council (ESRC) for funding BCS70, and the UK Data Service for storing the data and making them available. We started to work on this article during Prof Jacob's research stay at the University of Edinburgh as part of AQMeN (Applied Quantitative Methods Network), supported by the Economic and Social Research Council [grant number: ES/K006460/1]. Earlier versions of this article were presented at the European Consortium for Sociological Research (ECSR) Annual Conference 2016, Oxford, and the ISA RC28 Summer Meeting 2016, Bern. 


\begin{abstract}
Research on stratification and mobility has consistently shown that there is a direct impact of social origin on occupational destination net of educational attainment even for degreeholders. However, only a few studies applied a longitudinal and dynamic perspective on how intergenerational mobility shapes graduates' working careers. Using multilevel growth curve modelling and data from the 1970 British cohort study (BCS70), we contribute to this research by looking at the emergence of social inequalities during the first ten years since labour market entry. We further distinguish between graduates of different fields of study as we expect social disparities to develop differently due to differences in initial occupational placement and upward mobility processes. We find that parental class does not affect occupational prestige over and above prior achievement. Separate analyses by the field of study show that initial differences in occupational prestige and career progression do not differ between graduates from different classes of origin in STEM fields and arts and humanities. It is only in the social sciences that working class graduates start with lower occupational prestige but soon catch up with their peers from higher classes. Overall, our results indicate no direct effect of social origin on occupational attainment for degree-holders once we broaden our focus to a dynamic life course perspective.
\end{abstract}




\section{Introduction}

Numerous studies in research in social stratification and mobility have found that social origin and educational attainment are both strong determinants of occupational attainment. The Blau-Duncan model (1967) already addressed life-cycle variations in occupational attainment, but scholars have used dynamic approaches of intergenerational inequality in occupational careers only recently. In such a life course perspective, one asks whether initial differences in occupational attainment between individuals from different social origin and education groups perpetuate or increase over the life course or whether career developments offer the potential to compensate for initial differences (e.g. Mayer 2009; Sørensen 1975). A dynamic perspective on career advancement and progression is strongly intertwined with current conceptual advances in theories of cumulative (dis-)advantages (e.g. DiPrete and Eirich 2006).

To account for inter- and intra-generational social mobility a few recent studies have examined occupational trajectories and career progression of individuals with different social and educational backgrounds (e.g. Barone, Lucchini and Schizzerotto 2011; Härkönen and Bihagen 2011; Manzoni, Härkönen and Mayer 2014; Schulz and Maas 2012; Passaretta et al. 2018). Whereas this literature documented differences in career advancement between these groups and over time, we contribute to previous research by looking at within-group differences in occupational careers among degree-holders. It allows us to evaluate the impact of so-called 'qualitative' differences that are assumed to be increasingly important as more and more individuals attain higher education in the course of educational expansion (e.g. Lucas 2001). A growing literature in education, as well as stratification research, is concerned with graduates' field of study as an essential dimension for variation in labour market outcomes (e.g. Klein 2011; Van de Werfhorst 2002).

Several studies provide empirical evidence for differences between graduates from different fields of study in various labour market returns such as occupational prestige (Katz- 
Gerro and Yaish 2003; Shwed and Shavit 2006), class position (Sullivan et al. 2017) or earnings (Kim, Tamborini and Sakamoto 2015; Laurison and Friedman 2016; Sullivan et al. 2018). Existing research commonly uses 'snapshot' measures at labour market entry or at a particular age. However, occupational careers of graduates from different fields of study may evolve differently with some fields offering better chances of occupational upward mobility than others (cf. Rosenfeld 1992). In consequence, initial social inequalities in labour market outcomes might decrease over time in some fields, whereas in other fields social inequalities might even aggravate in the course of individuals' career progression.

In our article, we, therefore, analyse occupational trajectories by family background within graduates from different fields of study. The innovative contribution of the paper is threefold: first, our within-group comparison allows us to analyse the impact of social origin on career trajectories among the highest qualified that remains unobserved when modelling social inequalities across the life course and controlling for educational attainment (e.g. Manzoni, Härkönen and Mayer 2014). Second, this is the first study that considers the heterogeneous effects of social origin on intragenerational mobility by analysing social disparities in field-specific careers. Third, by observing a time-span of 10 years since entry into the labour market, we provide evidence for a potential long-term impact of social origin in the course of individuals' working careers. For our empirical analyses, we use data from the 1970 British Cohort Study and growth curve models to describe within- and betweenindividual occupational trajectories in a holistic way.

\section{Previous research: Social origin, field of study and labour market returns}

\subsection{Family background and graduate's career progression}

Since the seminal book of Blau and Duncan (1967), research in social stratification and mobility asks whether and to what extent social origin affects the labour market entry and later stages in the working life. The Blau-Duncan model already emphasised the importance 
of dynamic modelling and career progression for intergenerational mobility processes. However, many studies applied cross-sectional analyses to examine the direct effect of social origin on (graduates') labour market destination using population samples (e.g. Laurison and Friedman 2016; Wakeling and Savage 2015), considered outcomes at particular points in time during the career (Crawford and Vignoles 2014; Macmillan, Tyler and Vignoles 2015; Britton et al. 2016) or at specific ages (Crawford et al. 2016; Gugushvili, Bukodi and Goldthorpe 2017; Sullivan et al. 2017, 2018).

Jacob et al. (2015) and Bukodi and Goldthorpe (2011) go beyond these single observations of labour market outcomes, but still, use only two-points-in-time measures of individual careers. Both studies found initial social disparities in graduates' labour market outcomes that decreased across the working life in the UK. Based on REFLEX data, Jacob et al. (2015) showed that parental education has a positive effect on accessing the higher salariat class at labour market entry, but this result does not hold five years after graduation. Using three British cohort studies (1946, 1958, 1970), Bukodi and Goldthorpe (2011) examined individuals' occupational earnings. Among degree-holders, they identified social inequalities in occupational earnings in the first job but a smaller social gradient in the mid-thirties at the time of "occupational maturity".

In recent years, social stratification scholars have used new approaches of dynamic statistical modelling, i.e. multilevel growth curve models, to account for social origin differences in career advancement (e.g. Barone, Lucchini and Schizzerotto 2011; Härkönen and Bihagen 2011; Manzoni, Härkönen and Mayer 2014; Schulz and Maas 2012; Passaretta et al. 2018). However, all of these studies consider the whole working population without modelling interacting effects between social origin and educational attainment on career development. Also, previous research did not investigate more fine-grained social gradients within the same level of education.

\subsection{Graduates' field of study and career progression}


Field of study is an important determinant of graduates' labour market outcomes in the UK. Reimer et al. (2008) show that occupational status varies considerably between graduates from different fields. In particular, graduates from education and technical fields obtain a socioeconomic status above average whereas degree-holders in health and welfare and agricultural fields have the least favourable positions. In contrast, Kim and Kim (2003) found that graduates from education and humanities and arts are disadvantaged in access to the upper service class compared to graduates in health or engineering. Regarding financial returns, Chevalier (2011) shows a substantial heterogeneity in the average wages of UK graduates from different fields 3.5 years after graduation. Graduates from medicine, architecture and engineering have the highest wage returns; graduates from linguistics, communication and arts have the lowest. Bratti, Naylor and Smith (2007) consider wage returns of UK graduates from different fields at age 30 and show that graduates from the social sciences have the highest wage returns, graduates from the sciences are in the medium position, and students from the arts and humanities have the lowest wage returns among all fields (cf. Walker and Zhu 2011).

Only a few studies so far devoted attention to field-specific career advancement, and if so, they concentrated on earnings and in most cases were conducted in the US. Thomas and Zhang (2005) compared the initial wages of graduates to those achieved four years after graduation. They observed widening initial earnings differences between graduates from business, math, science, social sciences and graduates from education-related fields and history. Graduates from health and engineering started their career with high initial earnings but had a rather small increase across the four years after graduation. Finnie and Frenette (2003) analysed the earnings growth of Canadian graduates two and five years after graduation. They showed that (male) graduates from arts and humanities have the highest increase in average earnings over time, but still, lack behind the earnings of their peers graduating in other fields. Using data of a panel study combined with administrative tax data, 
Kim et al. (2015) found that STEM graduates have significant advantages regarding lifetime earnings gains compared to graduates from the social sciences.

Studies that address variation between fields of study in social gradients in labour market returns are rare and often limited to wages and income. In a Norwegian study, Hansen (2001) showed that social inequalities in income are smaller for graduates in STEM fields than for graduates in humanities and arts. For the Appalachian region in the US, Wolniak et al. (2008) found that pre-college family income is significantly associated with earnings for all fields except technical and applied fields. It is the greatest for STEM fields, smallest for education fields and health sciences with arts and humanities in-between. A recent study in the US by Manzoni and Streib (2018) showed no differences by parental education in earnings ten years after graduation for graduates in STEM majors but identified a earnings advantage for male graduates in arts and humanities with highly educated over their peers from less educated families. Similarly, Hällsten (2013) found that the effect of the class of origin on wages in the Swedish labour market is more substantial for graduates from humanities and arts than for graduates from the sciences. For the UK, Macmillan, Tyler and Vignoles (2015) considered variation in social gradients in access to higher managerial positions between different labour market sectors and found a positive association between parental class and entering a business, medical or law profession 3.5 years after graduation. None of these studies model variation in social inequalities across fields of study in career trajectories across the life course.

Summing up, we identify the following gaps in the literature: First, the few given 'snapshot' studies of graduates in the UK lacked a profound continuous empirical measurement of career trajectories by social origin and did not sufficiently answer how social inequalities develop across careers. Second, many studies were concerned with field-specific wages and earnings at labour market entry but did not consider field-specific career progression in occupations that may reveal different patterns. Finally, only a few studies 
investigated social inequalities in labour market outcomes by field of study and if so, did not consider career progression over time. However, the average effect of social origin on career trajectories may be misleading if social inequalities may decrease or increase across the working life in different fields.

\section{Theoretical considerations: social origin and field-specific careers}

To explain social gradients in labour market outcomes among individuals with the same education, previous literature on intergenerational mobility commonly refers to parents' economic, social and cultural capital that they transmit to their children (Bourdieu 1986; Coleman 1988). Parents' economic resources are expected to exert an influence on their offspring's labour market outcomes by, for instance, facilitating job search or residential mobility. Parents' social networks may be helpful in providing access to information about vacancies or potential employers. Cultural capital is considered to be beneficial in the recruitment process (cf. several contributions in Bernardi and Ballarino 2016).

Regarding career development after graduation, we need to distinguish between (1) initial labour market attainment directly after graduation (differences in intercepts), and (2) career progression over time (differences in slopes). We assume parental resources and support to be particularly helpful at labour market entry when employers hire applicants for the first time and signals of potential productivity are limited. Later in the career, employers can either observe employees' productivity directly or evaluate job applicants' accumulated work experience. Graduates from the lower class of origin may, therefore, compensate for initial disadvantages and catch up with their peers from the higher class of origin across the career. We expect that there are social class differentials at labour market entry. However, these class differentials vanish across the career due to steeper career progression of those from the lower class of origin (Hypothesis 1). For the UK, empirical results by Bukodi \& 
Goldthorpe (2011) and Jacob et al. (2015) already provide some support for the assumption of convergence between graduates' careers.

\section{-- Figure I here --}

To derive hypotheses on field-specific social class differentials in career advancement, we use a combination of theories on returns to field-specific skills, labour market allocation and promotion processes, and different labour market segments. First, a standard explanation for varying returns to fields of study is differences in the type of graduate skills (Heijke, Meng and Ramaekers 2003; Paglin and Rufolo 1990; Van de Werfhorst and Kraaykamp 2001). For example, Van de Werfhorst and Kraaykamp (2001) distinguish four types of endowments: cultural, economic, communicative and technical resources. Graduates with high levels of economic skills (e.g. business and administration, law) as well as those with technical resources (e.g. technical fields, maths and sciences) achieve more rewarding occupational positions in the labour market whereas graduating in fields linked to cultural skills (e.g. arts and humanities, education) yields the lowest labour market returns. However, these considerations refer to average returns in the labour market and do not imply any expectations about career progression. Assuming ceiling effects, graduates starting in highstatus positions at labour market entry may have fewer chances for improvement. Second, Klein (2011) argues that employers have imperfect information about labour market entrants' productivity and training costs and, therefore, graduates from fields providing 'soft skills' have only a weak signalling value due to their low occupational specificity. As tenure and work experience grows over time, however, graduates from unspecific fields can correct initial mismatches, move ahead in their careers and gain promotions as employers can judge them more accurately. Overeducation is less likely to occur among labour market entrants 
from 'occupation-specific' fields, and therefore there is less need for later corrections. Finally, the third line of theoretical explanations for field of study differences in career progression focuses on characteristics of graduates' jobs (e.g. Giesecke and Schindler 2008). This approach distinguishes between highly regulated labour market sectors with fewer opportunities (and less necessity) for occupational and career mobility and flexible market segments with high rates of temporary employment. Strong linkages between fields of study and occupational labour markets may, therefore, be advantageous for entry into high-status occupations and long-term occupational stability. Summing up, we can expect appropriate high-status positions at labour market entry for graduates from occupation-specific fields, such as STEM fields, and less intragenerational mobility over time compared to graduates in social sciences, arts and humanities.

Taking into account social origin, we assume parental resources to compensate for signalling of unspecific skills. Hence, for graduates from the arts and humanities, we expect vast social inequalities in initial labour market allocation. However, it is not clear whether and how social gradients develop across the career. On the one hand, students from lower classes of origin may overcome their initial disadvantages and catch up with those from higher class of origin as their real productivity becomes visible throughout their career. (Hypothesis 2a). On the other hand, if career advancement and promotion in the labour market of arts and humanities requires social and cultural resources, the advantages of offspring from higher classes may persist or become more significant due to cumulative advantages (Hypothesis $2 b)$.

Graduates from STEM fields have acquired more specific skills and qualifications compared to graduates from other fields. Thus, in the matching occupational labour market, parents from STEM graduates should have less leeway on job allocation procedures than in other partial labour markets. Also, we assume that STEM graduates enter occupations with relatively high task specificity and thus productivity is more dependent on what was taught 
during graduates' studies than on pre-existing skills or resources learned in the parental home. Therefore, we expect social inequalities among STEM graduates to be small both in initial placement and career progression (Hypothesis 3).

In the social sciences (incl. business and administration, economics), we expect degree-holders to enter medium-status occupational positions at labour market entry. Regarding career progression, we anticipate increasing social inequalities over time as social and cultural capital acquired in the parental home may facilitate access to and promotion in services and higher managerial positions (Jackson, Goldthorpe and Mills 2005). Also, for these graduates, intergenerational inheritance of business and self-employment may also play a crucial role for career progression. Hence, we expect a divergence of occupational positions over time due to a steeper slope for those from higher classes (Hypothesis 4). Figure II illustrates these field-specific hypotheses.

--- Figure II here ---

\section{Data, variables and methods}

\subsection{British Cohort Study (BCS70)}

For our empirical analysis, we use the 1970 British Cohort Study (BCS70) which follows the lives of people born in England, Scotland and Wales in a single week of 1970 (Elliott and Shepherd 2006). The original sample consisted of over 17,000 individuals. At the ages of five, 10 and 16 cohort members were followed-up by parental interview and examination. At the age of 26 , cohort members filled in a postal questionnaire and were then interviewed at four-year intervals from the age 30 onwards. In our paper, we use information collected in the third sweep (age 10, Butler and Bynner 2016) and sweeps six to eight (age 3038, University of London 2016a, 2016b, 2016c). We additionally draw on the 1970 British Cohort Study Activity Histories dataset (University of London 2016d) including retrospective information on activity histories from the age of 16 until the interview date of sweep 8, i.e. 
until age 38 (Hancock et al. 2011). We use retrospective information on the field of study, type of degree, marital status and number of children from sweeps 6 to 8 (age 30-38), and identified individual background information on the parental class, cognitive ability and ethnicity in the third sweep (age 10).

As with other longitudinal studies, the BCS70 is subject to considerable unit nonresponse across all waves. Only around 20 per cent of cohort members participated in all existing waves, over half of the cohort members dropped out of at least one wave but returned to the study and one third dropped from the study entirely (Mostafa and Wiggins 2015). Unit non-response is not random, mainly due to residential moves (Elliott and Shepherd 2006), but the predictive power of birth characteristics for unit non-response is consistently weak across waves and, therefore, undermines the efficacy of using non-response weights (Mostafa and Wiggins 2015; Cumming and Goldstein 2016). There are changes in the parental class composition across waves, but the proportion of fathers with manual occupations was mainly falling between wave 1 and wave 3 and did not considerably change afterwards (Mostafa and Wiggins 2015).

Our analytical sample consists of university graduates (undergraduate and postgraduate) who studied full-time and graduated from a UK HE institution until the age of 34. We observe graduates' career progression from their first significant job (lasting at least 6 months) until up to 10 years in the labour market. We exclude part-time students from our sample since their educational attainment runs in parallel to their occupational career and they are likely to have a more stable starting point after graduation when compared to full-time graduates. Overall, we identified 1347 graduates at age 34 who were full-time students, for whom information on the timing of graduation was available and who had at least one significant job during the observation period.

\subsection{Variables and operationalisation}


Table I provides an overview of the variables and descriptive statistics for 951 complete cases across 99,399 person-months. Our dependent variable is the Treiman occupational prestige scale (SIOPS) measured at each job across the observation period (Treiman 1977). This internationally standardised scale of occupational prestige shows remarkable stability across time and countries and is widely used in life course analysis of occupational attainment (Härkönen and Bihagen 2011; Härkönen, Manzoni and Bihagen 2016; Manzoni, Härkönen and Mayer 2014). To assign SIOPS scores to occupations, we recoded British SOC90 occupational codes into ISCO-88 codes. In our sample of graduates, SIOPS scores range between 15 (e.g. building construction labourers) and 78 (e.g. university professors and medical doctors), with an average of 54.79 and a standard deviation of 11.26.

\section{--- Table I here ---}

We measure months since labour market entry as the time since graduates started their first significant job, lasting at least six months. Since we intend to capture inequalities among graduates in career progression across the life course, we consider the time since individuals entered the labour market rather than their actual work experience. We follow graduates for up to ten years since their labour market entry, i.e. the measure is right-censored at 120 months. The average time that we observe graduates since labour market entry is around six years ( $\mathrm{SD}=34.52$ months). To avoid the predefinition of a functional form and to allow for variation in career progression across different stages, we model career progression as five 24-month splines and estimate linear slopes for each range.

Our measure of months since labour market entry does not account for career circumstances, career breaks and re-entry into the labour market due to family formation. Therefore, we control for part-time employment, the number of children and marital status. All these control variables are time-varying measures to account for changes in family circumstances across the occupational career. 
We operationalise our main independent variable, class of origin, with the 7-class 'analytical' version of the National Statistics Socio-Economic Classification (NS-SEC), an improved operationalisation of the EGP class schema (Goldthorpe 2007). To construct NSSEC codes, we rely on data on parents' occupation provided by Gregg (2012). We use the highest class position of both parents and aggregate this measure into three classes differentiating between salariat class (1. higher and 2. lower managerial and professional occupations), intermediate class (3. intermediate occupations, 4. small employers and own account workers, 5. lower supervisory and technical occupations) and working class (6. semiroutine and 7. routine occupations).

To operationalise field of study, we follow Bratti et al. (2007) and Walker and Zhu (2011) differentiating between three broad groups: 1) humanities (incl. arts.) 2) social sciences, 3) and fields in STEM (science, technology, engineering and mathematics) (for details on aggregation see Appendix Table AI). We additionally consider law and medicine as a fourth category as their professional career pathways are unique and, therefore, we refrain from mixing them with other fields. Field of study is operationalised as time-varying since individuals may change their field of study from undergraduate to postgraduate studies or may study for a second degree in a different field. The type of degree differentiates between first degree and postgraduate degree. Likewise, we measure this in a time-varying way so that it captures changes in educational attainment.

We also control for background characteristics such as gender and ethnic origin. Due to the small sample size, we only differentiate between individuals originating from the UK and individuals originating from a different country.

Following Breen and Goldthorpe (2001), we operationalize cognitive ability by totalling all four conducted British Ability Scales (BAS) assessments (Elliott, Murray and Pearson 1979) - two verbal subscales (word definitions and word similarities) and two non- 
verbal subscales (recall of digits and matrices) - and standardised it to a mean of 100 and a standard deviation of 15 .

\subsection{Analytic strategy}

To analyse the association between graduates' social origin and occupational attainment over the early working life, we use growth curve modelling (Halaby 2003; Steele 2008). Growth curve modelling allows for the inclusion of time-constant and time-varying variables while putting particular emphasis on the modelling of time, in our case, career progression over the early life course and its association with covariates (i.e. differences in career progression by covariates).

Our baseline growth curve model is as follows:

$$
\begin{aligned}
& y_{i t}=\beta_{0}+\sum_{s=1}^{5} \beta_{1 s} \text { Time }_{i t s}+\beta_{2} \text { Class }_{i}+\beta_{3} \text { Ethnic }_{i}+\beta_{4} \text { Cog }_{i}+\beta_{5} \text { Field }_{i t}+\beta_{6} \text { Degree }_{i t}+\beta_{7} \text { Marstat }_{i t} \\
& +\beta_{8} \text { Child }_{i t}+\beta_{9} \text { Part }_{i t}+\mu_{i}+\varepsilon_{i t}
\end{aligned}
$$

The model includes the five 24-months splines, dummy variables for class of origin, ethnic origin, fields of study, type of degree, marital status, part-time employment and linear specifications for cognitive ability and the number of children. It also contains a personspecific unobserved factor $\mu$ (random effect) and a time-varying error term $\varepsilon$. The intraclass correlation - which we calculate based on the variances of the error terms $\left(\rho=\sigma_{\mu}^{2} /\left(\sigma_{\mu}^{2}+\sigma_{\varepsilon}^{2}\right)\right)$ - shows us how much of the overall variance in occupational prestige is due to variation between individuals and due to variation within individuals across the early and mid-career. The stronger this intraclass correlation, the more inequality between graduates in occupational prestige exists and the fewer within-changes we can identify across graduate careers.

The $\beta_{1 s}$ estimates indicate the average monthly change in occupational attainment within the 24-month splines. The remaining $\beta$ coefficients indicate the strength of 
associations between the respective variables and occupational prestige averaged across the early working career. To test our first hypothesis, we extend our baseline model by including interaction terms between graduates' class of origin and our five splines for time since labour market entry. To test the hypotheses on field-specific social inequalities, we run our extended model including the interaction between graduates' class of origin and spline for the three different field groups separately.

\section{Results}

\subsection{Occupational prestige across the early career}

Table II indicates a series of growth curve models. To decompose the total variance into variance between individuals and within-variance across the career, our first model (M0) is an empty model without any covariates. Model M1 introduces five 24-months splines to show how occupational prestige changes over the first ten years after labour market entry. Model M2 accounts for the class of origin, ethnicity and gender (also includes the family variables and an indicator of part-time employment). Model M3 investigate whether social inequalities in occupational prestige are due to differences in cognitive ability. To account for differences in graduate characteristics that may explain a class of origin gap in occupational prestige, we include the field of study and type of degree in the last model (M4).

The intraclass correlation coefficient (ICT) as shown in M0 indicates to what extent the total variation in occupational prestige is due to differences between graduates rather than within-differences across the career. In our sample, the ICT shows that 71 per cent of the overall variance is due to differences in occupational prestige between graduates. Thus, differences in occupational prestige between graduates rather emerge at the beginning of the career, and there is only modest career mobility over time that corrects for these initial differences. Compared to working populations in Germany (Manzoni, Härkönen and Mayer 2014) or Italy (Barone, Lucchini and Schizzerotto 2011), however, the ICT is smaller, i.e. 
career mobility (among graduates) is higher than in these settings. It may indicate that the UK labour market is more dynamic than labour markets in other countries or that graduate labour markets offer more leeway for career progression or both.

Model 1 in Table II introduces the five 24-month splines. Graduates' make progress in their career predominantly in the first two years after they gained their first significant job: The average graduate gains $3.02(24 \times 0.126)$ SIOPS points across the first 24 months. In the following two years, career progression slows down but graduates, on average, still achieve considerable gains (1.032 SIOPS points, $24 \times 0.043$ ). After four years since the first significant job, graduates appear to be more established in their careers and change in occupational prestige is limited but not entirely stopped. Graduates, on average, gain 1.56 SIOPS points $(24 \times 0.027+24 \times 0.017+24 \times 0.021)$ across the following six years. Overall, graduates gain, on average, 5.6 SIOPS points across the first ten years since labour market entry.

Model 2 includes the background characteristics of class of origin, ethnic origin and gender. While all estimates are in the expected direction, effect sizes are rather small. Graduates from an intermediate class background gain, on average, 0.521 SIOPS points and working-class background gain, on average, 1.829 SIOPS points less than graduates whose parents belong to the salariat class. Hence, among UK graduates, prestige differences by class of origin across the occupational career are rather small. Accounting for cognitive ability (M3), these class of origin differences further reduce but do not entirely vanish when differentiating between graduates from working class and salariat class background. The last model (M4) additionally accounts for the field of study and type of degree. Differences between graduates from fields of study regarding occupational prestige are small and do not show a clear pattern. Graduates who achieve a postgraduate degree have a substantial advantage in occupational prestige compared to degree-holders. Accounting for these graduate characteristics reduces the contrast between graduates from working class and 
salariat class background in occupational prestige marginally. Averaged across graduate careers, the direct effect of class of origin on occupational prestige net of cognitive ability and horizontal educational differences appears to be negligible.

\subsection{Occupational career progression by social origin and field of study}

So far, the effects of career progression analysed in Table II refer to average careers. We now turn to the results on career progression by class of origin as expressed in hypothesis 1. Figure III shows the predicted SIOPS scores by class of origin and time since labour market entry while holding the other variables at their reference value (see full estimates in appendix table AII). In this figure, we can see small differences in occupational prestige between graduates from working-class background and graduates from both intermediate and salariat class background at labour market entry. This difference becomes slightly stronger across the first two years as graduates from salariat and intermediate class backgrounds have steeper growth curves than graduates from working-class background. In the following two years, occupational prestige continues to grow to the same extent as previously for workingclass graduates, while growth slows down for graduates with higher-class backgrounds. Hence, graduates from working-class backgrounds catch up with their peers from more advantaged backgrounds after four years in the labour market.

To test our field-specific hypothesis, we predict SIOPS scores by class of origin and time since labour market entry for the different field of study groups separately (see full estimates in appendix table AIII), results are shown in Figure IV. Unfortunately, we cannot consider social inequalities in career progression within law and medicine as the number of cases is too small to conduct such an analysis. In humanities, class of origin differences are minimal. If at all, working-class graduates tend to be disadvantaged in their career progression in the first two years after gaining a first significant job but they catch up with

their peers from more advantaged backgrounds afterwards. Likewise, we do not find 
substantial social inequalities in career progression for graduates from STEM fields. Working-class graduates achieve slightly higher scores of occupational prestige at all stages of their career. In contrast, working-class graduates in the social sciences have, on average, a prestige score at labour market entry that is about five SIOPS points lower than the score of graduates from more advantaged backgrounds. Graduates from working-class backgrounds can overcome this initial disadvantage and catch up with their peers from higher-class backgrounds eight years after graduation.

\section{Discussion}

We examined early occupational careers of degree-holders in the UK and the long-term influence of social origin up to 10 years after labour market entry. Differentiating between graduates of different fields allowed us to describe the evolution of social inequalities on top of the educational level. Given the increasing share of degree-holders in the UK (and elsewhere) qualitative differences such as field of study may have become increasingly crucial for processes of social stratification. By adopting a dynamic approach looking at intergenerational occupational mobility, we wanted to detect whether and to what extent social inequalities in the early career are strengthened or mitigated, and whether initial disparities and differences in career progression vary by field of study.

Averaged across the whole observation period of 10 years after labour market entry, we did not find significantly lower occupational attainment for graduates from working-class backgrounds compared to graduates from higher classes of origin. When we looked more closely at the effect of social origin at different stages of the career, our illustration of career patterns showed lower occupational attainment of working-class offspring at labour market entry. However, due to a steeper career progression, they catch up with the careers of their peers from higher classes of origin four years after labour market entry. This result provides 
evidence for our first hypothesis and is in line with previous research (Jacob, Klein and Iannelli 2015; Bukodi and Goldthorpe 2011)

Regarding the development of occupational prestige in different fields of study, progression and social origin differences of career growth vary by field of study. In line with our expectations, we found social inequalities in occupational prestige neither at labour market entry nor in career progression in STEM fields. Contrary to our assumptions, there were also no social gradients in occupational careers for graduates in arts and humanities. We observed more pronounced inequalities among graduates in the social sciences but in the opposite way that we expected. Working-class graduates attain significantly lower occupational prestige at labour market entry compared to other graduates. However, they catch up with their peers and achieve the same level of occupational prestige a few years after labour market entry.

Our results contribute to research on social inequalities in graduates' labour market outcomes. In line with previous results on UK graduates using the same dataset (e.g. most recently Sullivan et al. 2017, 2018) we did not find a substantial direct effect of social origin on graduates' average occupational attainment over the period of ten years after labour market entry. However, we found different patterns of career progression that we would not have been able to detect in 'snapshot' analyses. Graduates from disadvantaged backgrounds have lower occupational attainment only at labour market entry and due to a steeper progression achieve about the same level of occupational prestige than their peers rather early in their career. Ad hoc explanations could be that the graduate labour market is rather formalised and bureaucratic or that those working class children that achieve a degree are a selective group of students with productivity-enhancing characteristics. Our results also support the thesis that a degree is an "equaliser" for labour market outcomes as social origin has no effect on occupational prestige over and above attaining a degree in the long run (Torche 2011). The 'null' result of no social gradients in the labour market is not common in social stratification 
research where scholars more frequently stress and empirically find cumulative (dis)advantages.

Our results also highlight the importance of considering heterogeneity in social inequalities in the labour market within broader educational groups. We only found social class differences in occupational prestige at labour market entry among graduates from the social sciences but only marginal differences among graduates from the humanities and STEM fields. This variation in the social gradient in occupational prestige is hidden if we just look at the average association between social origin and graduate careers. We cannot empirically test however why this is the case. What we can exclude is the possibility that graduates from higher classes of origin have social or 'soft' skills that are advantageous in gaining access to higher managerial occupations as these skills should be valuable and give them an advantage over graduates from working-class origin throughout the career. It could be that parental social capital is essential to gain access to prestigious entry positions for social science graduates. It could also be that graduates from the social sciences have a high risk of being overeducated at labour market entry and parental resources protect graduates from advantaged backgrounds from having to accept a vertically mismatched position. However, these potential mechanisms could also be valid for the humanities for which we did not find these social inequalities.

Our study has several limitations: First, our study is merely descriptive in analysing the career trajectories of graduates from different social backgrounds. A causal interpretation of our estimates rests on the strong assumption that there are no important unmeasured factors that influence degree attainment in different fields of study, occupational attainment and its progression, and at the same time vary by social origin. Graduates from lower class backgrounds may be a selective group regarding characteristics such as motivation, aspirations, preferences, extracurricular and other activities that, in turn, affect labour market 
entry and career progression. Compared to previous studies that focus on graduates, our study is, however, unique in accounting for cognitive ability differences between graduates from different backgrounds and as such may address a considerable part of the selectivity in our graduate sample.

Our second limitation is the small sample size and weak statistical power especially when we focus on social inequalities in career progression within fields of study. Compared to graduate surveys, our data provide the advantage of looking at graduates' long-term career mobility in a more dynamic perspective. Nevertheless, in future research, these results need to be replicated with larger samples.

Third, our paper solely focused on the outcome of occupational prestige. Extending our analysis with income appears to be promising as income has a stronger variation than occupational prestige and is less prone to ceiling effects. Hence, inter- and intra-generational mobility patterns may be different from what we observe in our analysis when using income (Sullivan et al. 2018; Witteveen and Attewell 2017 for the US).

Finally, we did not assess career progression beyond ten years after labour market entry. We cannot exclude the possibility that social inequalities emerge again in the later stages of the life course. Also, social disparities may go beyond occupational stratification, i.e. regarding allocation into different labour market sectors, different employment statuses, and different geographic locations as has been examined by Manzoni and Streib (2018) in the US context.

Given the insights gained by applying a dynamic perspective on the career progression of graduates, we suggest that longitudinal approaches on intergenerational mobility need to be further developed, both theoretically and empirically, to gain a better understanding of underlying mechanisms on when and how social inequalities emerge, increase or even decline over the life-course. 


\section{References}

Barone, C., Lucchini, M. and Schizzerotto, A. 2011 'Career Mobility in Italy: A Growth Curves Analysis of Occupational Attainment in the Twentieth Century', European Societies 13: $377-400$.

Bernardi, F. and Ballarino, G. 2016 Education, Occupation and Social Origin: A Comparative Analysis of the Transmission of Socio-Economic Inequalities, Cheltenham, UK: Edward Elgar Publishing.

Blau, P.M. and Duncan, O.D. 1967 The American Occupational Structure, New York: Wiley.

Bourdieu, P. 1986 'The Forms of Capital' in J. G. Richardson (ed) Handbook for Theory and Research for the Sociology of Education, New York: Greenwood Press.

Bratti, M., Naylor, R. and Smith, J. 2007 'Different Returns to Different Degrees? Evidence from the British Cohort Study 1970', Warwick Economic Research Papers 783.

Breen, R. and Goldthorpe, J.H. 2001 'Class, Mobility and Merit: The Experience of Two British Birth Cohorts', European Sociological Review 17(2): 81-101.

Britton, J., Shephard, N., Vignoles, A. and Dearden, L. 2016 'How English domiciled graduate earnings vary with gender, institution attended, subject and socio-economic background', IFS Working Paper W16/06

Bukodi, E. and Goldthorpe, J.H. 2011 'Class Origins, Education and Occupational Attainment in Britain', European Societies 13(3): 347-375.

Butler, N., Bynner, J.M. 2016 University of London. Institute of Education. Centre for Longitudinal Studies. 1970 British Cohort Study: Ten-Year Follow-Up, 1980. [data collection]. 6th Edition. UK Data Service. SN: 3723, http://doi.org/10.5255/UKDA-SN-37237

Chevalier, A. 2011 'Subject choice and earnings of UK graduates', Economics of Education Review 30(6): 1187-1201.

Coleman, J.S. 1988 'Social Capital in the Creation of Human Capital', The American Journal of Sociology 94: 95-120.

Crawford, C., Gregg, P., Macmillan, L., Vignoles, A. and Wyness, G. 2016 'Higher education, career opportunities, and intergenerational inequality', Oxford Review of Economic Policy 32(4): 553-575.

Crawford, C. and Vignoles, A. 2014 'Heterogeneity in graduate earnings by socio economic background', IFS Working Paper W14/30.

Cumming, J. and Goldstein, H. 2016 'Handling attrition and non-response in longitudinal data with an application to a study of Australian youth', Longitudinal and Life Course Studies 7(1): 53-63.

DiPrete, T.A. and Eirich, G.M. 2006 'Cumulative Advantage as a Mechanism for Inequality: A Review of Theoretical and Empirical Developments', Annual Review of Sociology 32(1): p.271-297.

Elliott, C.D., Murray, D.J. and Pearson, L.S. 1979 British Ability Scales, Slough: NFER. Elliott, J. and Shepherd, P. 2006 'Cohort profile: 1970 British Birth Cohort (BCS70)', International Journal of Epidemiology 35(4): 836-843.

Finnie, R. and Frenette, M. 2003 'Earning Differences by Major Field of Study: Evidence from three Cohorts of Recent Canadian Graduates', Economics of Education Review 22(2): 179-192.

Giesecke, J. and Schindler, S. 2008 'Field of study and flexible work: A comparison between Germany and the UK', International Journal of Comparative Sociology 49(4-5): 283-304.

Goldthorpe, J.H. 2007 'Social Class and the Differentiation of Employment Contracts' in J. 
H. Goldthorpe (ed) On Sociology. Volume Two: Illustration and Retrospect, Stanford: Stanford University Press.

Gregg, P. 2012 Occupational Coding for the National Child Development Study (1969, 19912008) and the 1970 British Cohort Study (1980, 2000-2008). [data collection]. University of London. Institute of Education. Centre for Longitudinal Studies, [original data producer(s)]. UK Data Service. SN: 7023, http://doi.org/10.5255/UKDA-SN-7023-1

Gugushvili, A., Bukodi, E. and Goldthorpe, J.H. 2017 'The Direct Effect of Social Origins on Social Mobility Chances: "Glass Floors" and "Glass Ceilings" in Britain', European Sociological Review 33(2): 305-316.

Halaby, C.N. 2003 'Panel Models for the Analysis of Change and Growth in Life Course Studies' in J. Mortimer and M. J. Shanahan (eds) Handbook of the Life Course, Hingham, MA: Kluwer Academic.

Hällsten, M. 2013 'The Class-origin Wage Gap: Heterogeneity in Education and Variations Across Market Segments', British Journal of Sociology 64(4): 662-690.

Hancock, M., Elliott, J., Johnson, J. and Bukodi, E. 2011 'British Cohort Study (1970): Activity Histories (1986-2008)', University of London. Institute of Education. Centre for Longitudinal Studies.

Hansen, M.N. 2001 'Education and Economic Rewards. Variations by Social-Class Origin and Income Measures', European Sociological Review 17(3): 209-231.

Härkönen, J. and Bihagen, E. 2011 'Occupational Attainment and Career Progression in Sweden', European Societies 13: 451-479.

Härkönen, J., Manzoni, A. and Bihagen, E. 2016 'Gender inequalities in occupational prestige across the working life: An analysis of the careers of West Germans and Swedes born from the 1920s to the 1970s', Advances in Life Course Research 29: 41-51.

Heijke, H., Meng, C. and Ramaekers, G. 2003 'An Investigation into the Role of Human Capital Competences and their Pay-off', International Journal of Manpower 24(7): 750-773. Jackson, M., Goldthorpe, J.H. and Mills, C. 2005 'Education, Employers and Class Mobility', Research in Social Stratification and Mobility 23: 3-33.

Jacob, M., Klein, M. and Iannelli, C. 2015 'The Impact of Social Origin on Graduates' Early Occupational Destinations - An Anglo-German Comparison', European Sociological Review 31(4): 460-476.

Katz-Gerro, T. and Yaish, M. 2003 'Higher Education: is more better? Gender Differences in Labour Market Returns to Tertiary Education in Israel', Oxford Review of Education 29(4): 571-592.

Kim, A. and Kim, K.-W. 2003 'Returns to Tertiary Education in Germany and the UK: Effects of Fields of Study and Gender', MZES Working Paper 62.

Kim, C., Tamborini, C.R. and Sakamoto, A. 2015 'Field of study in College and Lifetime Earnings in the United States', Sociology of Education 88(4): 320-339.

Klein, M. 2011 'Higher Education and Non-Pecuniary Returns in Germany: Tracing the Mechanisms behind Field of Study Effects at the Start of the Career', Irish Educational Studies 30(2): 247-264.

Laurison, D. and Friedman, S. 2016 'The Class Pay Gap in Higher Professional and Managerial Occupations', American Sociological Review 81(4): 668-695.

Lucas, S.R. 2001 'Effectively Maintained Inequality: Education Transitions, Track Mobility, and Social Backrounds Effects', American Journal of Sociology 106(6): 1642-1690.

Macmillan, L., Tyler, C. and Vignoles, A. 2015 'Who Gets the Top Jobs? The Role of Family Background and Networks in Recent Graduates' Access to High-status Professions', Journal of Social Policy 44(03): 487-515.

Manzoni, A., Härkönen, J. and Mayer, K.U. 2014 'Moving On? A Growth-Curve Analysis of Occupational Attainment and Career Progression Patterns in West Germany', Social Forces 92(4): 1285-1312. 
Manzoni, A. and Streib, J. 2018 'The Equalizing Power of a College Degree for FirstGeneration College Students: Disparities Across Institutions, Majors, and Achievement Levels', Research in Higher Education First Online: 21 July 2018.

Mayer, K.U. 2009 'New Directions in Life Course Research', Annual Review of Sociology 35(1): 413-433.

Mostafa, T. and Wiggins, R. 2015 'The impact of attrition and non-response in birth cohort studies: a need to incorporate missingness strategies', Longitudinal and Life Course Studies 6(2): 131-146.

Paglin, M. and Rufolo, A. 1990 'Heterogeneous Human Capital, Occupational Choice and Male-Female Earnings Differences', Journal of Labor Economics 8(1): 123-144.

Passaretta, G., Barbieri, P., Wolbers, M.H.J. and Visser, M. 2018 'The direct effect of social origin on men's occupational attainment over the early life course: An Italian-Dutch comparison', Research in Social Stratification and Mobility 56:1- 11.

Reimer, D., Noelke, C. and Kucel, A. 2008 'Labor Market Effects of Field of Study in Comparative Perspective: An Analysis of 22 European Countries', International Journal of Comparative Sociology 49(4-5): 233-256.

Rosenfeld, R.A. 1992 'Job Mobility and Career Processes', Annual Review Sociology 18: 3961.

Schulz, W. and Maas, I. 2012 'Studying Career Success - The Role of Resources and Norms for Occupational Status Attainment in The Netherlands, 1865-1940', European Sociological Review 28(2): 220-240.

Shwed, U. and Shavit, Y. 2006 'Occupational and economic attainments of college and university graduates in Israel', European Sociological Review 22(4): 431-442.

Sørensen, A.B. 1975 'The Structure of Intragenerational Mobility', American Sociological Review 40: 456-471.

Steele, F. 2008 'Multilevel Models for Longitudinal Data', Journal of the Royal Statistical Society: Series A (Statistics in Society) 171: 5-19.

Sullivan, A., Parsons, S., Green, F., Wiggins, R.D. and Ploubidis, G. 2018 'Elite universities, fields of study and top salaries: Which degree will make you rich?', British Educational Research Journal 44(4): 663-680.

Sullivan, A., Parsons, S., Green, F., Wiggins, R.D. and Ploubidis, G. 2017 'The path from social origins to top jobs : social reproduction via education 1', British Journal of Sociology First published: 03 October 2017.

Thomas, S.L. and Zhang, L. 2005 'Post-baccalaureate wage growth within four years of graduation: The effects of college quality and college major', Research in Higher Education 46(4): 437-459.

Torche, F. 2011 'Is a College degree still the great equalizer? Intergenerational mobility across levels of schooling in the United States', American Journal of Sociology 117(3): 763807.

Treiman, D.J. 1977 Occupational Prestige in Comparative Perspective, New York: Academic Press.

University of London. Institute of Education. Centre for Longitudinal Studies 2016a 1970 British Cohort Study: Twenty-Nine-Year Follow-Up, 1999-2000. [data collection]. 4th Edition. Joint Centre for Longitudinal Research, [original data producer(s)]. UK Data Service. SN: 5558, http://doi.org/10.5255/UKDA-SN-5558-3

University of London. Institute of Education. Centre for Longitudinal Studies 2016b 1970 British Cohort Study: Thirty-Four-Year Follow-Up, 2004-2005. [data collection]. 4th Edition. UK Data Service. SN: 5585, http://doi.org/10.5255/UKDA-SN-5585-3

University of London. Institute of Education. Centre for Longitudinal Studies (2016c). 1970 British Cohort Study: Thirty-Eight-Year Follow-Up, 2008-2009. [data 
collection]. 4th Edition. UK Data Service. SN: 6557, http://doi.org/10.5255/UKDA-SN-6557$\underline{3}$

University of London. Institute of Education. Centre for Longitudinal Studies 2016d 1970 British Cohort Study: Activity Histories, 1986-2008. [data collection]. 2nd Edition. UK Data Service. SN: 6943, http://doi.org/10.5255/UKDA-SN-6943-2

Wakeling, P. and Savage, M. 2015 'Entry to elite positions and the stratification of higher education in Britain', The Sociological Review 63: 290-320.

Walker, I. and Zhu, Y. 2011 'Differences by Degree: Evidence of the Net Financial Rates of Return to Undergraduate Study for England and Wales', Economics of Education Review 30(6): 1177-1186.

Van de Werfhorst, H.G. 2002 'Fields of Study, Acquired Skills and the Wage Benefit from a Matching Job', Acta Sociologica 45(4): 287-303.

Van de Werfhorst, H.G. and Kraaykamp, G. 2001 'Four Field-Related Educational Resources and Their Impact on Labor, Consumption, and Sociopolitical Orientation', Sociology of Education 74(4): 296-317.

Witteveen, D. and Attewell, P. 2017 'Family Background and Earnings Inequality among College Graduates', Social Forces 4: 1539-1576.

Wolniak, G.C., Seifert, T.A., Reed, E.J. and Pascarella, E.T. 2008 'College majors and social mobility', Research in Social Stratification and Mobility 26(2): 123-139. 
TABLE I. SUMMARY STATISTICS (N=99,399 PERSON-MONTHS FROM 951 GRADUATES)

\begin{tabular}{|c|c|c|c|c|}
\hline & Mean/percentage & SD & Min & Max \\
\hline SIOPS prestige score & 54.29 & 11.26 & 15 & 78 \\
\hline Months since first significant job & 58.68 & 34.52 & 1 & 120 \\
\hline $\mathrm{CM}$ is female & 0.49 & 0.50 & 0 & 1 \\
\hline \multicolumn{5}{|l|}{ Class of origin } \\
\hline Working class & 0.12 & 0.32 & 0 & 1 \\
\hline Intermediate class & 0.31 & 0.46 & 0 & 1 \\
\hline Salariate class & 0.57 & 0.49 & 0 & 1 \\
\hline Ethnic origin is non-UK & 0.04 & 0.18 & 0 & 1 \\
\hline Cognitive ability & 113.52 & 12.20 & 70.44 & 151.20 \\
\hline \multicolumn{5}{|l|}{ Field of study } \\
\hline Humanities & 0.30 & 0.46 & 0 & 1 \\
\hline Social sciences (incl. professions) & 0.32 & 0.47 & 0 & 1 \\
\hline STEM fields & 0.32 & 0.47 & 0 & 1 \\
\hline Law and medicine & 0.06 & 0.24 & 0 & 1 \\
\hline $\mathrm{CM}$ has postgraduate degree & 0.10 & 0.30 & 0 & 1 \\
\hline \multicolumn{5}{|l|}{ Marital status } \\
\hline Single & 0.67 & 0.47 & 0 & 1 \\
\hline Married & 0.31 & 0.46 & 0 & 1 \\
\hline Divorced & 0.02 & 0.13 & 0 & 1 \\
\hline \multicolumn{5}{|l|}{ Number of children } \\
\hline Zero & 0.86 & 0.35 & 0 & 1 \\
\hline One & 0.11 & 0.31 & 0 & 1 \\
\hline Two & 0.03 & 0.17 & 0 & 1 \\
\hline Three or more & 0.00 & 0.06 & 0 & 1 \\
\hline $\mathrm{CM}$ in part-time employment & 0.07 & 0.25 & 0 & 1 \\
\hline
\end{tabular}

Source: British Cohort Study 1970 (BCS70); Note: Statistics pertain to complete cases in our analytical sample 
TABLE II. SUMMARY OF GROWTH CURVE MODELS PREDICTING OCCUPATIONAL PRESTIGE ( $\mathrm{N}$ = 99,993 PERSON-MONTHS FROM 951 GRADUATES)

\begin{tabular}{|c|c|c|c|c|c|}
\hline & M0 & M1 & M2 & M3 & M4 \\
\hline \multirow[t]{2}{*}{24 months ( 2 yrs) or less } & & $0.126^{* * *}$ & $0.125^{* * *}$ & $0.125^{* * *}$ & $0.120^{* * *}$ \\
\hline & & $(0.015)$ & $(0.015)$ & $(0.015)$ & $(0.015)$ \\
\hline \multirow[t]{2}{*}{$25-48$ months (3-4 yrs) } & & $0.043^{* * *}$ & $0.047^{* * *}$ & $0.047^{* * *}$ & $0.045^{* * *}$ \\
\hline & & $(0.012)$ & $(0.013)$ & $(0.011)$ & $(0.013)$ \\
\hline \multirow[t]{2}{*}{$49-72$ months (5-6 yrs) } & & $0.027^{*}$ & $0.033^{* *}$ & $0.033^{* *}$ & $0.030^{* *}$ \\
\hline & & $(0.011)$ & $(0.011)$ & $(0.011)$ & $(0.011)$ \\
\hline \multirow[t]{2}{*}{$73-96$ months (7-8 yrs) } & & 0.017 & $0.027^{*}$ & $0.027^{*}$ & $0.024^{*}$ \\
\hline & & $(0.011)$ & $(0.012)$ & $(0.012)$ & $(0.012)$ \\
\hline \multirow[t]{2}{*}{$97-120$ months (9-10 yrs) } & & $0.021^{*}$ & $0.029^{* *}$ & $0.029^{* *}$ & $0.027^{*}$ \\
\hline & & $(0.010)$ & $(0.011)$ & $(0.011)$ & $(0.011)$ \\
\hline \multirow[t]{2}{*}{ Female (ref. male) } & & & -0.525 & -0.331 & -0.291 \\
\hline & & & $(0.640)$ & $(0.636)$ & $(0.822)$ \\
\hline \multirow[t]{2}{*}{ Non-UK origin (ref. UK) } & & & -0.372 & 0.712 & 0.586 \\
\hline & & & $(1.716)$ & (1.684) & $(1.652)$ \\
\hline \multicolumn{6}{|l|}{$\begin{array}{l}\text { Parental class (ref. Salariat } \\
\text { class) }\end{array}$} \\
\hline \multirow[t]{2}{*}{ Intermediate class } & & & -0.521 & -0.001 & 0.018 \\
\hline & & & $(0.708)$ & $(0.707)$ & $(0.679)$ \\
\hline \multirow[t]{2}{*}{ Working class } & & & -1.829 & -0.930 & -0.655 \\
\hline & & & $(0.984)$ & $(0.978)$ & $(0.945)$ \\
\hline \multirow[t]{2}{*}{ Cognitive ability } & & & & $0.129^{* * *}$ & $0.120^{* * *}$ \\
\hline & & & & $(0.027)$ & $(0.027)$ \\
\hline
\end{tabular}

Field of study (ref.

humanities)

Social sciences 
Postgraduate (ref.

undergraduate)

Intercept

$$
54.010^{* * *}
$$$$
50.160^{* * *}
$$

Variance components

Between-individual 93.257

91.980

91.305

88.943

82.235

Within-individual

38.267

36.236

35.826

35.826

35.666

Intraclass correlation (rho)

0.71

0.72

0.72

0.71

0.70

$\mathrm{Chi}^{2}$

133.36

162.97

192.93

215.61

Source: British Cohort Study 1970 (BCS70); Note: models M2-M4 control for marital status, number of children and part-time employment. Robust standard errors are in parentheses. ${ }^{*} p<0.05,{ }^{* *} p<0.01,{ }^{* * *} p<0.001$. 


\section{Figures}

FIGURE I. SCHEMATIC ILLUSTRATION OF HYPOTHESIS 1: GRADUATES' CAREER DEVELOPMENT BY SOCIAL ORIGIN

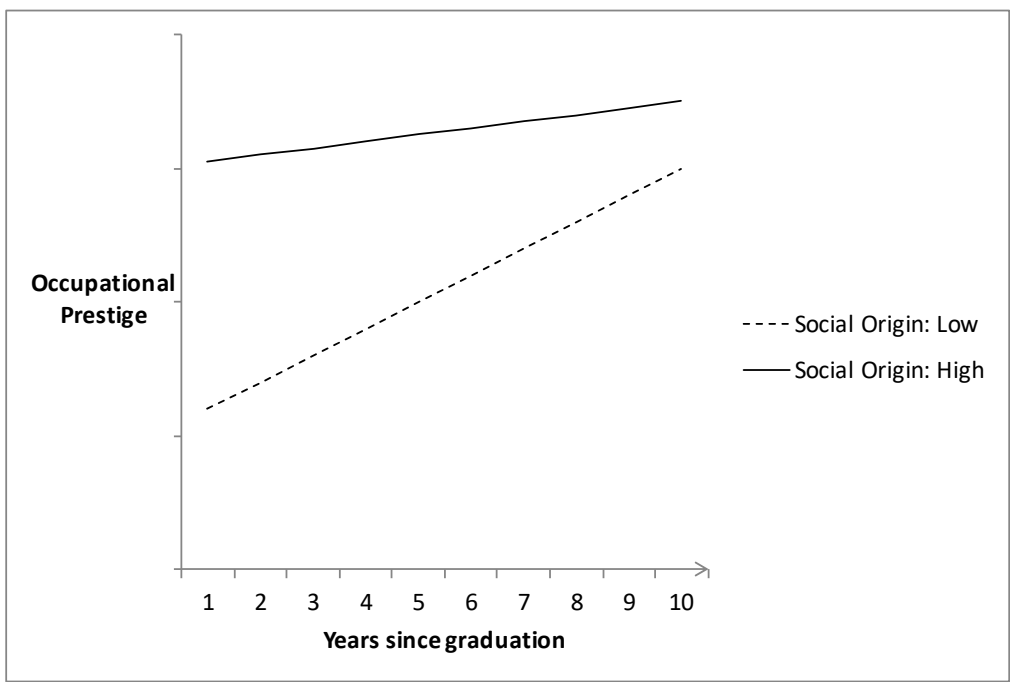


FIGURE II. SCHEMATIC ILLUSTRATION OF HYPOTHESES 2a, 2b, 3 AND 4: GRADUATES' CAREER DEVELOPMENT BY SOCIAL ORIGIN IN DIFFERENT FIELDS OF STUDY
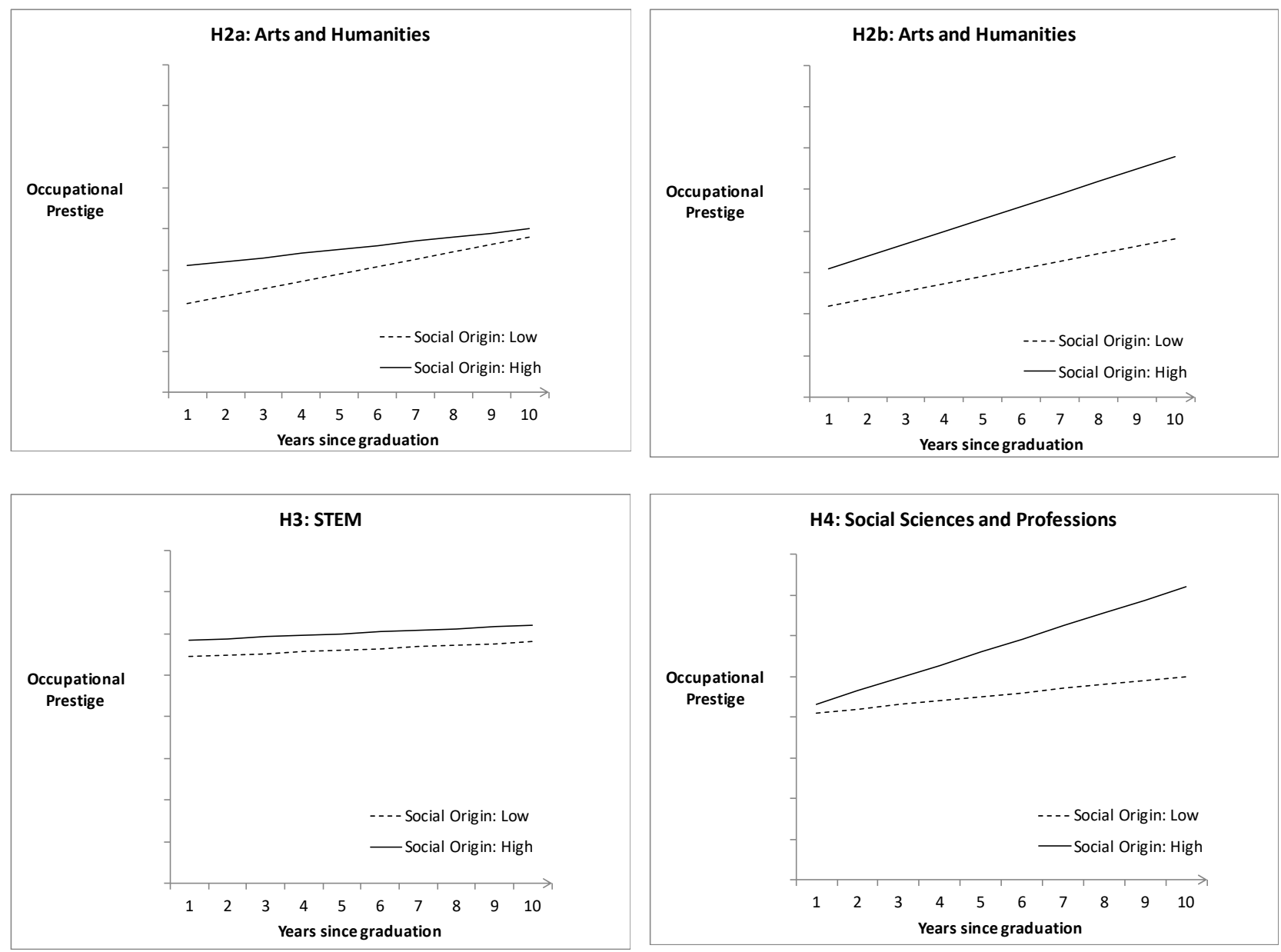
FIGURE III. PREDICTED OCCUPATIONAL PRESTIGE BY PARENTAL CLASS

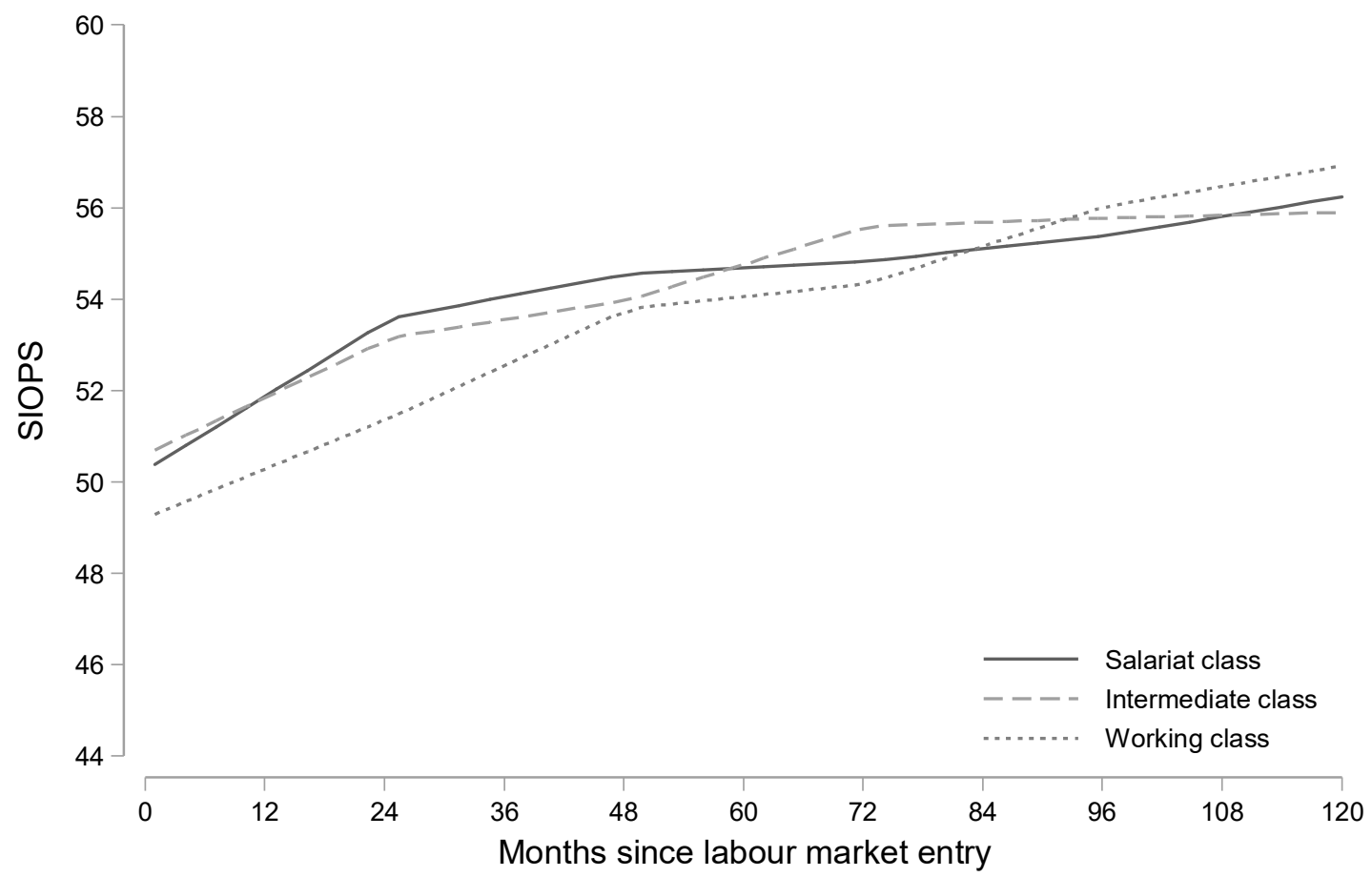

Source: British Cohort Study 1970 (BCS70); Note: Estimates obtained from growth curve model M5 in Appendix Table AII. 
FIGURE IV. PREDICTED OCCUPATIONAL PRESTIGE BY PARENTAL CLASS ACROSS DIFFERENT FIELDS OF STUDY
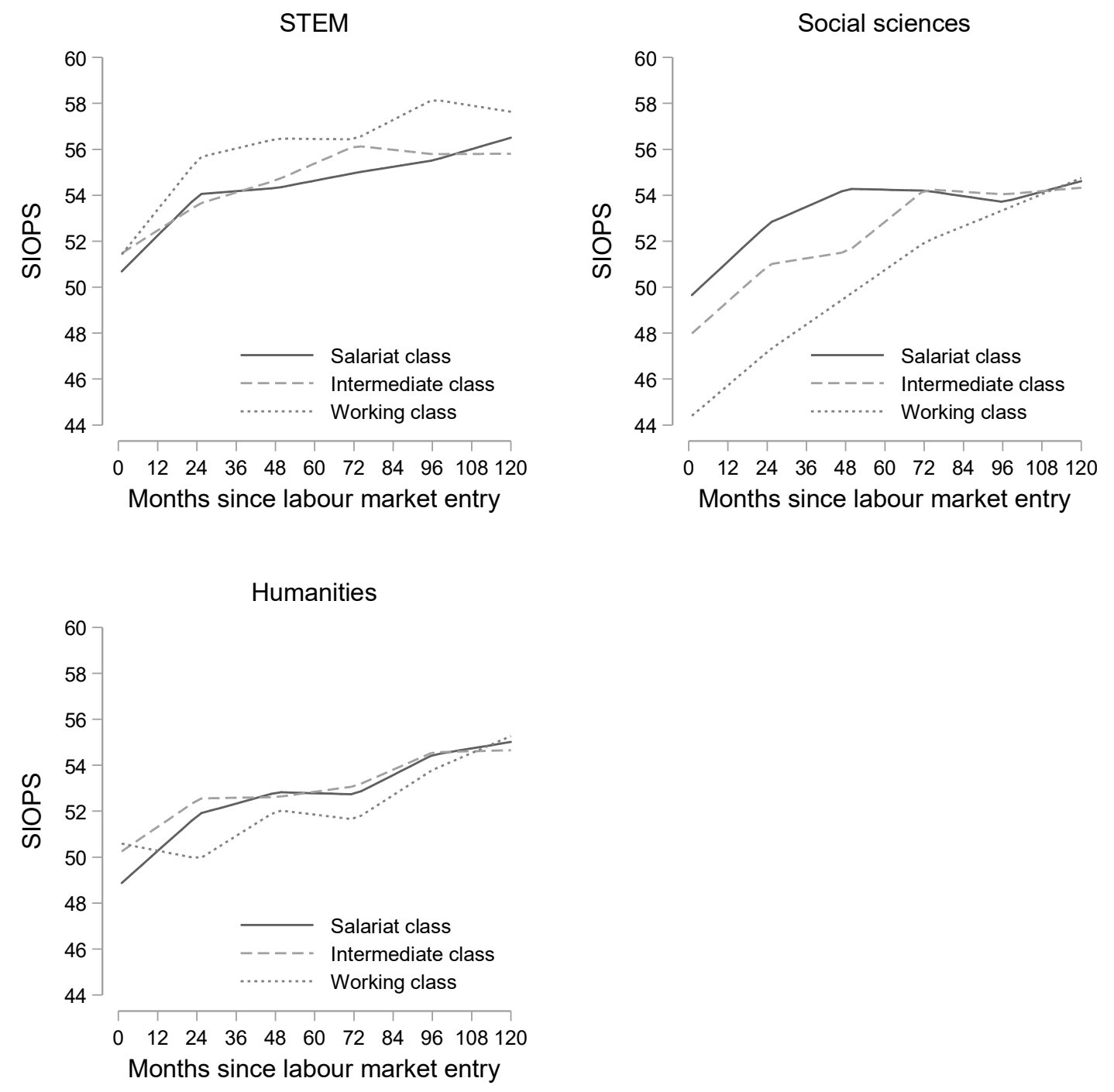

Source: British Cohort Study 1970 (BCS70); Note: Respective estimates obtained from models 6-8 in Appendix Table AIII. 


\section{Online Appendix}

Table AI. Aggregation of fields of study into three main groups

\begin{tabular}{|c|c|c|c|}
\hline Humanities & Social Sciences & STEM & Law and medicine \\
\hline English & Accountancy & Architecture & Law \\
\hline Art & Psychology & Engineering & Medicine \\
\hline Linguistics & Statistics & Agriculture & Dentistry \\
\hline American studies & Applied social sciences & Science & \\
\hline Ancient History & Business & Biology & \\
\hline Applied Language Studies & Economics & Chemistry & \\
\hline Drama & Banking, insurance and finance & Geology & \\
\hline Film, radio and television & Behavioural science & Physics & \\
\hline Textile Design & Estate management & Mechanical Engineering & \\
\hline Acting studies & Geography & Computer Science & \\
\hline Archaeology & Health studies & Biochemistry & \\
\hline Arts \& Design & Management & Math & \\
\hline Education & Pharmacology & Astronomy & \\
\hline Graphic design & Physiology & Building Engineering & \\
\hline Community studies & Physiotherapy & Civil Engineering & \\
\hline Cultural studies & Political science & Construction & \\
\hline Classical civilisation & Public policy & Electronics & \\
\hline Communication studies & Sociology & Environmental Science & \\
\hline Dance studies & Social policy & Information Technology & \\
\hline Design illustration & Social anthropology & Manufacturing Engineering & \\
\hline European languages & Urban studies & Marine Biology & \\
\hline Fashion design & Zoology & Mechanical Engineering & \\
\hline Fine art & Anatomy & Cell and Molecular Biology & \\
\hline French & Animal science & Earth sciences & \\
\hline German & Marketing & Ecology & \\
\hline Hispanic studies & Nursing studies & Technology & \\
\hline History & Pathology & Telecommunications & \\
\hline Libriarianship & Public administration & & \\
\hline Media studies & Social work & & \\
\hline \multicolumn{4}{|l|}{ Modern studies } \\
\hline \multicolumn{4}{|l|}{ Music } \\
\hline \multicolumn{4}{|l|}{ Performing arts } \\
\hline Philosophy & & & \\
\hline
\end{tabular}


Physical education

Religion

Spanish

Sport studies

Theology

Classical music

Photography 
Table AII. Growth curve models predicting occupational prestige by class of origin ( $N=99,993$ person-months from 951 graduates)

\section{M5}

24 months ( 2 yrs) or less

$0.135^{* * *}$

$(0.022)$

25-48 months (3-4 yrs)

$0.040^{* *}$

$(0.016)$

49-72 months (5-6 yrs)

0.012

$(0.014)$

73-96 months (7-8 yrs)

0.023

$(0.017)$

97-120 months (9-10 yrs)

$0.036^{*}$

$(0.014)$

Female (ref. male)

$-0.284$

$(0.832)$

Non-UK origin (ref. UK)

0.643

(1.664)

Parental class (ref. Salariat class)

Intermediate class

0.356

$(0.999)$

Working class

$-1.039$

$(1.420)$

Cognitive ability

$0.121^{* * *}$

$(0.027)$

Field of study (ref. humanities)

Social sciences

STEM fields

$-0.672$ 
Intermed. class x 24 months or less

$-0.032$

$(0.032)$

Intermed. class * 25-48months

$-0.006$

$(0.025)$

Intermed. class x 49-72months

$0.056^{*}$

$(0.023)$

Intermed. class x 73-96months

$-0.006$

$(0.025)$

Intermed. class x 97-120months

$-0.015$

$(0.024)$

Working class x 24months

$-0.046$

$(0.044)$

Working class x 25-48months

0.059

$(0.043)$

Working class x 49-72months

0.011

$(0.034)$

Working class x 73-96months

0.048

$(0.035)$

Working class x 97-120months

0.001

$(0.036)$

Intercept

$50.419^{* * *}$

$(2.040)$ 
Variance components

Between-individual

82.636

Within-individual

35.560

Intraclass correlation (rho)

0.70

$\mathrm{Chi}^{2}$

223.91

Source: British Cohort Study 1970 (BCS70); Note: model controls for marital status, number of children and part-time employment. Robust standard errors are in parentheses. ${ }^{*} p<0.05,{ }^{* *} p<0.01,{ }^{* * *} p<0.001$. 
Table AIII. Growth curve models predicting occupational prestige across 10 years by class of origin for humanities ( $N=29,355$ person-months from 289 graduates), social sciences ( $N=31,572$ personmonths from 308 graduates) and STEM ( $N=32,287$ person-months from 312 graduates)

\begin{tabular}{|c|c|c|c|}
\hline 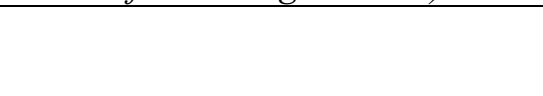 & M6 (Humanities) & $\begin{array}{c}\text { M7 (Social } \\
\text { sciences) }\end{array}$ & M8 (STEM) \\
\hline \multirow[t]{2}{*}{24 months ( 2 yrs $)$ or less } & $0.127^{* *}$ & $0.132^{* * *}$ & $0.142^{* * *}$ \\
\hline & $(0.040)$ & $(0.039)$ & $(0.039)$ \\
\hline \multirow[t]{2}{*}{ 25-48 months (3-4 yrs) } & 0.039 & $0.062^{*}$ & 0.011 \\
\hline & $(0.029)$ & $(0.030)$ & $(0.026)$ \\
\hline \multirow[t]{2}{*}{$49-72$ months (5-6 yrs) } & -0.004 & -0.003 & 0.028 \\
\hline & $(0.026)$ & $(0.023)$ & $(0.025)$ \\
\hline \multirow[t]{2}{*}{ 73-96 months (7-8 yrs) } & $0.072^{* *}$ & -0.021 & 0.023 \\
\hline & $(0.026)$ & $(0.033)$ & $(0.030)$ \\
\hline \multirow[t]{2}{*}{$97-120$ months (9-10 yrs) } & 0.023 & 0.038 & 0.042 \\
\hline & $(0.024)$ & $(0.029)$ & $(0.023)$ \\
\hline \multirow[t]{2}{*}{ Female (ref. male) } & 0.838 & 0.195 & -0.707 \\
\hline & $(1.271)$ & $(1.094)$ & $(1.269)$ \\
\hline \multirow[t]{2}{*}{ Non-UK origin (ref. UK) } & -0.705 & 2.365 & -1.514 \\
\hline & $(2.727)$ & $(3.301)$ & $(2.159)$ \\
\hline \multicolumn{4}{|l|}{ Parental class (ref. Salariat class) } \\
\hline \multirow[t]{2}{*}{ Intermediate class } & 1.409 & -1.664 & 0.836 \\
\hline & $(1.699)$ & $(1.827)$ & $(1.756)$ \\
\hline \multirow[t]{2}{*}{ Working class } & 1.871 & $-5.247^{*}$ & 0.695 \\
\hline & $(2.527)$ & $(2.128)$ & $(2.817)$ \\
\hline \multirow[t]{2}{*}{ Cognitive ability } & $0.119^{*}$ & 0.083 & $0.120^{* *}$ \\
\hline & $(0.047)$ & $(0.051)$ & $(0.044)$ \\
\hline \multirow[t]{2}{*}{ Postgraduate (ref. undergraduate) } & $-7.608^{* * *}$ & 3.361 & 6.875 \\
\hline & $(1.326)$ & $(2.632)$ & $(3.930)$ \\
\hline Intermed. class $* 24 \mathrm{~m}$ & -0.030 & -0.006 & -0.051 \\
\hline
\end{tabular}




\begin{tabular}{|c|c|c|c|}
\hline & $(0.063)$ & $(0.057)$ & $(0.054)$ \\
\hline \multirow[t]{2}{*}{ Intermed. class $* 25-48 \mathrm{~m}$} & -0.037 & -0.039 & 0.032 \\
\hline & $(0.040)$ & $(0.046)$ & $(0.042)$ \\
\hline \multirow[t]{2}{*}{ Intermed. class * 49-72m } & 0.024 & $0.118^{* *}$ & 0.035 \\
\hline & $(0.038)$ & $(0.040)$ & $(0.042)$ \\
\hline \multirow[t]{2}{*}{ Intermed. class $* 73-96 \mathrm{~m}$} & -0.010 & 0.011 & -0.038 \\
\hline & $(0.038)$ & $(0.052)$ & $(0.040)$ \\
\hline \multirow[t]{2}{*}{ Intermed. class $* 97-120 \mathrm{~m}$} & -0.020 & -0.026 & -0.041 \\
\hline & $(0.044)$ & $(0.045)$ & $(0.032)$ \\
\hline \multirow[t]{2}{*}{ Working class $* 24 \mathrm{~m}$} & $-0.155^{* *}$ & -0.012 & 0.037 \\
\hline & $(0.053)$ & $(0.080)$ & $(0.090)$ \\
\hline \multirow[t]{2}{*}{ Working class $* 25-48 \mathrm{~m}$} & 0.050 & 0.037 & 0.023 \\
\hline & $(0.082)$ & $(0.065)$ & $(0.056)$ \\
\hline \multirow[t]{2}{*}{ Working class $* 49-72 \mathrm{~m}$} & -0.013 & 0.103 & -0.029 \\
\hline & $(0.062)$ & $(0.069)$ & $(0.043)$ \\
\hline \multirow[t]{2}{*}{ Working class $* 73-96 \mathrm{~m}$} & 0.019 & 0.079 & 0.050 \\
\hline & $(0.067)$ & $(0.064)$ & $(0.056)$ \\
\hline \multirow[t]{2}{*}{ Working class * 97-120m } & 0.038 & 0.020 & -0.064 \\
\hline & $(0.058)$ & $(0.051)$ & $(0.073)$ \\
\hline \multirow[t]{2}{*}{ Intercept } & $49.212^{* * *}$ & $49.378^{* * *}$ & $49.366^{* * *}$ \\
\hline & $(1.501)$ & $(1.241)$ & $(1.575)$ \\
\hline \multicolumn{4}{|l|}{ Variance components } \\
\hline Between-individual & 79.422 & 80.114 & 80.777 \\
\hline Within-individual & 32.187 & 39.207 & 32.344 \\
\hline Intraclass correlation (rho) & 0.71 & 0.67 & 0.71 \\
\hline $\mathrm{Chi}^{2}$ & 80.99 & 100.59 & 90.94 \\
\hline
\end{tabular}

